Received Date : 12-Jul-2016

Revised Date : 09-Sep-2016

Accepted Date : 19-Sep-2016

Article type : Original Article

\title{
The Management of Acne Vulgaris in Primary Care: A cohort study of consulting and prescribing patterns using CPRD
}

\section{Running Title: Acne Primary Care Cohort}

\author{
N.A. Francis ${ }^{1}$, K. Entwistle ${ }^{1}$, M. Santer ${ }^{2}$, A.M. Layton ${ }^{3}$, E.A. Eady ${ }^{4}$, C.C. Butler ${ }^{5}$ \\ ${ }^{1}$ Division of Population Medicine, School of Medicine, Cardiff University \\ ${ }^{2}$ Primary Care and Population Sciences, University of Southampton \\ ${ }^{3}$ Hull York Medical School, Universities of York \& Hull \\ ${ }^{4}$ Harrogate and District NHS Foundation Trust \\ ${ }^{5}$ Nuffield Department of Primary Health Care Sciences, University of Oxford
}

Corresponding author:

Dr Nick A Francis, Division of Population Medicine, School of Medicine, Cardiff University, Neuadd Meirionnydd, Heath Park, Cardiff, CF14 4YS. francisna@cf.ac.uk

Funding:

This study was supported by funding from Health and Care Research Wales (formerly the National Institute for Social and Health Care Research) in the form of a fellowship for Dr Francis (HF-11-01). The funder played no role in data collection or analysis or manuscript preparation.

Conflicts of Interest:

AL has received honoraria for lecturing (unrestricted content) at educational meetings and in relation to consultancy for Galderma, MEDA, Gillette and GlaxoSmithKline/ Steifel. AE has received honoraria in relation to consultancy for GSK/Stiefel (unpaid), Galderma, Gillette and Origimm. CCB received an honorarium from Galderma for contribution to a discussion on acne. All authors declare no other conflicts of interest.

What's already known about this topic?

- Most patients with acne self-manage or are managed in primary care.

- Studies suggest low consultation rates and medication adherence for acne.

- Longitudinal care with follow-up appointments could improve medication use and outcomes.

- Oral and topical antibiotic use can promote the development of antimicrobial resistance.

This article has been accepted for publication and undergone full peer review but has not been through the copyediting, typesetting, pagination and proofreading process, which may lead to differences between this version and the Version of Record. Please cite this article as doi: 10.1111/bjd.15081

This article is protected by copyright. All rights reserved. 


\section{What does this study add?}

- Two-thirds of patients who have a new acne consultation have no follow-up consultation during the subsequent 90 days.

- Oral antibiotics are the most common acne related medications (ARM) prescribed, normally without co-prescribing topical non-antibiotic agents.

- Following an initial prescription, $60.1 \%$ and $38.6 \%$ of patients received no further ARM prescriptions in the following 90 days and one year respectively.

\section{Abstract}

Background: Effective management of acne vulgaris in primary care involves support (usually provided over a number of consultations) and prescribing effective treatments. However, consulting and prescribing patterns for acne in primary care are not well described.

Objective: To describe the rate of primary care consultations and follow-up consultations; prescribing patterns, including overall use of acne related medications (ARM) and initial and follow-up prescribing, for acne vulgaris in the UK.

Methods: UK primary care acne consultations and prescriptions for ARMs were identified in the Clinical Practice Research Datalink (CPRD). Annual consultation rates (between 2004 and 2013) by age and gender, new consultations and consultations in the subsequent year; prescribing trends, prescribing during a new consultation and over the subsequent 90 days and year were calculated, using number of registered patients as the denominator.

Results: $65.9 \%$ of patients who had a new acne consultation had no further acne consultations in the subsequent year. $26.6 \%, 25.2 \%, 23.5 \%$ and $2.8 \%$ of patients were prescribed no ARM, an oral antibiotic, a topical antibiotic, or an oral plus topical antibiotic respectively during a new acne consultation. $59.9 \%$ and $38.5 \%$ of patients prescribed an ARM received no further ARM prescriptions in the following 90 days and one year respectively, despite most prescriptions being for 2 months or less. Prescribing rates for lymecycline and topical combined clindamycin/benzoyl peroxide increased substantially between 2004 and 2013. There were no important changes in consultation rates between 2004 and 2013.

Conclusion: These data suggest that patients with acne are receiving sub-optimal initial choice of ARMs, longitudinal care and prescribing.

\section{INTRODUCTION}

Acne vulgaris ('acne' hereafter) is one of the most common dermatological conditions managed by health services in the developed world. ${ }^{1}$ It has a significant impact on quality of life ${ }^{2,3}$ and is associated with mental health problems and suicide. ${ }^{1,4}$ Acne is a chronic condition that usually begins in the early teens and is present in over $40 \%$ of those in their thirties. ${ }^{5}$ In the UK, most medical care for people with acne is provided in primary care.

This article is protected by copyright. All rights reserved. 
Acne can be effectively treated with a range of antibiotic and non-antibiotic approaches. However, for medications to be effective they need to be used regularly. Little is known about how frequently acne medications are initiated, and once started, for how long they are used. Most of these medications have a slow onset of action and need to be used for several weeks or months before full effectiveness is seen. Therefore, it is important to ensure that patients receive adequate information about use of the medication, and ideally monitoring and support to encourage ongoing use (for at least 3-4 months). Guidance for clinicians recommends close monitoring and follow-up appointments. ${ }^{6,7}$

Consulting in primary care for acne allows for accurate diagnosis and assessment of severity; an opportunity to discuss the evidence for effectiveness of various treatments, seek the patient's ideas and expectations, dispel myths, and come to a shared decision regarding a treatment plan; and education about the slow onset of action of most acne medications and the need for prolonged treatment. Early follow-up consultations are recommended by UK guidelines ${ }^{6}$ and are important in order to provide ongoing support and encourage regular use of medication, monitor for adverse effects and provide advice about changes to treatment regimens where necessary; and monitor for adverse psychological impacts. However, it is not clear how often patients consult in primary care, both in terms of new consultations and follow-up consultations. In addition, there are few data about medications primary care clinicians prescribe for acne and how frequently they are prescribed to an individual patient. There are increasing concerns about the development of antibiotic resistance in acne, ${ }^{8}$ and UK guidelines recommend restricting antibiotics to second or third line treatments and combining oral antibiotics with topical treatments such as benzoyl peroxide (to reduce resistance), or retinoids or adapalene (to reduced comedones). ${ }^{6,7}$

We set out to determine the rates and trends in primary care consultations for acne, and the frequency of subsequent (follow-up) acne consultations in a patient who has had a new (index) consultation for acne. In addition, we aimed to determine which medications are prescribed in primary care for acne, how these have changed, and the patterns of prescribing during the year following an index consultation.

\section{METHODS}

This retrospective longitudinal cohort study of patients presenting to their General Practice with acne vulgaris makes use of UK Clinical Practice Research Datalink (CPRD) data. ${ }^{9}$ This large database of anonymised patient records represents approximately 9\% of the UK population. Data are extracted from over 500 primary care practices across the UK representing over 5.5 million individuals. ${ }^{10}$ For this

This article is protected by copyright. All rights reserved. 
study, data were extracted on patients who consulted with any acne read-code between 01/01/04 and 31/12/13. Read codes included acne varioliformis, acne frontalis, acne necrotica, other acne, acne vulgaris, blackhead, acne conglobate and cystic acne. We excluded unusual codes such as acne fulminans, chlorine acne, iodine acne, and colloid acne. We also excluded children aged less than 8 years and codes for acne neonatorum and infantile acne as pre-pubertal acne is uncommon and usually non-inflammatory, and we excluded those with no gender identified in the data. At each consultation point, patients were classified into one of four age bands (8-11 years, 12-18 years, 19-29 years and 30 or more years of age). We did not restrict on the basis of recorded consultation type (i.e. surgery consultation, telephone consultation, home visit). CPRD undertake data quality checks and flag patients as having acceptable data or not. For all analyses, and for calculating denominators, we only used patients who had been flagged as having acceptable data.

\section{Consultation rates}

Age and gender specific consultation rates per 1,000 person-years were calculated using age and gender specific denominators calculated based on patients registered with CPRD practices during the same time period. The number of registered patients during each month was averaged over each study year. Annual age and gender specific rates were plotted for $2004-2013$, and average annual rates were tabulated.

In order to better describe acne consultation patterns following an initial consultation, we identified a cohort of patients with an 'index' acne consultation occurring between 2005 and 2012, no acne consultations and no primary care prescriptions for acne related medications (ARM; see prescribing section for list of ARMs) in the year prior to their index consultation, and at least a year of follow-up data available after their index consultation (patients who died or transferred to a different surgery during their follow-up year were excluded). We then followed each patient for the year following their index consultation and counted the number of subsequent acne consultations, and time to first subsequent acne consultation, for each participant.

This article is protected by copyright. All rights reserved. 


\section{Prescribing}

Prescribing was assessed by examining the following as ARMs based on guidance in the British National Formulary $(B N F)^{(11)}$ : oral oxytetracycline, tetracycline, doxycycline, lymecycline, minocycline and erythromycin; topical antibiotics (erythromycin or clindamycin), topical retinoid (and retinoidlike) preparations, topical benzoyl peroxide and azelaic acid, and topical combination products; and co-cyprindiol (Dianette). Prescriptions for oral antibiotics that were for less than 28 days and erythromycin suspensions were excluded because these are less likely to have been prescribed for acne. Combined oral contraceptives other than co-cyprindiol can be used for treating acne, but were not included because they are commonly prescribed for contraception or menstrual problems and it is not possible using CPRD data to determine whether they were being prescribed for acne or not. Relevant items were grouped together on the basis of their active ingredient(s). ARMs that were prescribed during the ten-year study period were identified for all patients who had one or more Read codes for acne at any point during the ten-year period, whether they occurred at the time of an acne consultation or not. Total annual ARM prescription rates were calculated and plotted for each ARM.

To further describe the pattern of ARM use, we used the cohort with an index consultation and at least a year of follow-up data available described earlier. We calculated the number and type of ARMs that were prescribed at the index consultation, during the subsequent 90 days, and during the subsequent year. We classified each ARM into one of the following four groups: topical antibiotic, topical non-antibiotic, oral antibiotic and co-cyprindiol. Consultations were then classified as involving prescription of one of the four groups described above or one of the following combinations: oral antibiotic + topical non-antibiotic, oral antibiotic + topical antibiotic, co-cyprindiol + any topical agent, and other combinations. Along with 'no ARM', this resulted in nine groups. We then identified the prescribing group for each index consultation and the changes in group (including to 'no ARM') during the subsequent 90 days and 364 days. Prescribing at the index consultation and changes during the first 90 days were then plotted using a Sankey diagram. ${ }^{11}$ Finally, we identified the quantity of medication prescribed for each ARM, and described the median and interquartile range. Oral antibiotic prescriptions where the quantity prescribed was greater than 672 (equivalent to four times a day for six months) were excluded as these were thought likely to be errors.

This study was approved by the Independent Scientific Advisory Committee (Refs: 14-095 and 14096), the independent body that approves use of CPRD data. Study protocols and programing code can be made available upon request. Stata statistical software (version 13) was used for all analyses. ${ }^{12}$ 


\section{RESULTS}

\section{Consultation Rates}

318,772 patients had been assigned a code for acne at some point during $2004-2013$. We removed $230(0.07 \%)$ patients who had no consultations where they were aged 8 or over and 7 patients with missing data on gender, leaving 716,272 consultations in 318,535 patients. The highest consultation rates were found in 12-18 year old girls, followed by 12-18 year old boys, 19-29 year old women and 19-29 year old men (Table 1 and Fig. 1). Consultation rates were low for 8-11 year olds and those aged 30 or over. There did not appear to be any significant trends in consultation rates over the period from 2004 to 2013 (Fig. 1).

\section{Re-consultations}

167,573 patients aged 8 years or over met the criteria for inclusion in the cohort. Of these, $66.1 \%$ had no further acne consultations during the following year, $21.8 \%$ had one, and $12.1 \%$ had two or more. Of those who did have a subsequent acne consultation during the following year, more than half (55.5\%) occurred after first 90 days, and there was slightly less early follow-up in younger patients (Table 2).

\section{Prescribing}

Out of the 318,535 patients over 8 who had had one or more acne consultations, 41,185 (12.9\%) were not prescribed any ARMs during 2004 - 2013, leaving 277,350 (87.1\%) who were prescribed 2,081,351 ARM prescriptions during the ten-year period. Oxytetracyline was the most common ARM to be prescribed in 2004 (6.5 items per 1,000 PY), but lymecycline prescribing increased substantially over the study period, and became the most common oral ARM from 2008 (11.8 items per 1,000 PY in 2013)(Fig. 2). Doxycycline prescribing increased to a lesser extent and the prescribing of all other oral antibiotics and co-cyprindiol decreased over the study period. The prescribing of oral isotretinoin increased ten-fold from 0.01 to 0.1 items per 1,000 PY from 2004 to 2009, but then decreased slightly to 0.8 items per 1,000 PY in 2013. The most commonly prescribed topical agent in 2004 was clindamycin (3.1 items per 1,000 PY), but prescribing of topical combined clindamycin and benzoyl peroxide(Duac ${ }^{\top M}$ ) increased substantially over the study period and was the most commonly prescribed topical ARM from 2008 on (8.8 items per 1,000 PY in 2013)(Fig. 3).

This article is protected by copyright. All rights reserved. 
A total of 167,573 patients aged 8 or over were identified as having a new acne consultation (index consultation), with no prior acne consultations or ARM prescriptions in the previous 12 months. $26.7 \%$ of these were prescribed no ARM during their index consultation. The most common ARM prescribed during the index consultation was oral antibiotic alone (24.9\% of consultations). The frequency of prescribing other ARM combinations at the index consultation is given in Table 3. 67.5\% of patients were prescribed no ARMs during the 90 days following the index consultation. A third of these $(39,314)$ were not prescribed an ARM at the index consultation as well as not being prescribed an ARM in the following 90 days. Nearly half $(20,481$ (49.0\%)) of those prescribed an oral antibiotic at the index consultation had no further ARM prescriptions in the following 90 days, and the majority of those prescribed topical antibiotics $(27,670(70.0 \%))$ and topical non-antibiotics $(15,926(76.3 \%))$ were prescribed no further ARMs in the following 90 days. Figure 4 gives a graphical representation of which ARMs (or combinations) patients were prescribed at baseline and in the following 90 days. 78,567 (46.9\%) patients were prescribed no ARMs during the year following their index consultation. Of the 122,764 patients who were prescribed an ARM at their index consultation, $73,817(60.1 \%)$ and 47,408 (38.6\%) were prescribed no further ARMs during the subsequent 90 days and year respectively. Very few patients were prescribed oral isotretinoin, either at the index consultation or during the following year.

The quantity of ARMs per prescription was approximately equivalent to 2-3 months' worth for most patients (Table 4).

\section{DISCUSSION}

\section{Summary of main findings}

In this analysis of routinely collected UK general practice data we found that consultation rates for acne in primary care are relatively low, and were largely stable between 2004-2013. Using population distribution data from 2013, our data suggest that there are around 934,000 general practitioner (GP) consultations for acne a year, and that a typical general practice of 7,000 patients would expect to have 115 consultations for acne per year: 1 with 8-11 year olds, 25 with 12-18 year old boys, 29 with 12-18 year old girls, 13 with 19-29 year old men, 28 with 19-29 year old women, 4 with men aged 30 or more and 15 with women aged 30 or more. Only one-third of patients who have a new acne consultation (no acne consultations or prescriptions in the preceding year) have a follow-up acne consultation in the subsequent year. A quarter of patients with a new acne consultation are prescribed no ARMs during their initial consultation, two-thirds receive no ARMs during the following three months (even though quantities prescribed are generally for less than 3 months), and only 
about a half receive one or more ARMs in the subsequent year. Oral antibiotics (without any prescribed topical medication) were the most common ARM to be prescribed at the first consultation, followed by topical medication containing antibiotics and then topical medication without antibiotics. Oxytetracycline was the most commonly prescribed oral ARM in 2004, but prescribing of lymecycline increased steadily throughout the period up to 2013, and became the most common oral ARM from 2009 on. Co-cyprindiol prescribing decreased slightly over the same period. Oral isotretinoin was rarely prescribed initially, but use increased ten-fold between 2004-2009. Clindamycin was the most commonly prescribed topical ARM in 2004, but prescribing of topical combined clindamycin/BPO increased about five-fold during the period under study, and topical combined clindamycin/BPO was the most commonly prescribed topical ARM from 2007 on. Most non-antibiotic ARMs were prescribed at relatively low rates, but prescribing of the third generation topical retinoid, adapalene (as a single agent) and combined adapalene/BPO (Epiduo ${ }^{\mathrm{TM}}$ ) increased from around 2010/11 on.

Our study included a large representative sample and data from across England and Wales. We were able to use data for a ten-year period allowing for a description of consultation and prescribing rate trends over time. We were able to account for patients joining or leaving practices in our denominators, and this is significant as $29 \%$ of the patients consulting for acne transferred out of the practice before 2013 and 38\% of the patients in our study joined the practice between 2004 and 2013. CPRD uses data collected as part of routine clinical care, and therefore the data may not always be relevant for research purposes. We did not exclude on the basis of consultation type and therefore may have included some out-of-hours, secondary care or spurious consultations as primary care consultations. This is unlikely to have been a frequent occurrence, but our consultation rates and follow-up rates may be a slight overestimate of actual rates. Prescribing data are well coded in UK primary care, however prescriptions are not directly linked to a diagnosis (they are linked to a 'consultation', which may or may not have one or more diagnostic codes), and therefore we cannot be certain that all prescriptions were actually for acne. Most ARMs are fairly specific for acne, but oral antibiotics could have been prescribed for other indications. We dealt with this by identifying a cohort of patients with a 'new' acne consultation and at least a year of follow-up data, following them over a year, and by only including prescriptions of oral antibiotics that were for 28 days or more. The Read code system that is used in UK primary care does not allow for coding of severity or site, and so we are not able to present data on this. We excluded prescriptions for oral antibiotics that were for less than 28 tablets (equivalent to 7 days) and oral erythromycin suspensions, as most of these are unlikely to be for acne. However, it is possible that some of these prescriptions were for acne. Topical treatments containing BPO are available without a prescription in the UK, so it is possible that some of the patients who appear to be using 'no ARMs' are actually using over the counter BPO. Combined 
oral contraceptives (COC) are not licensed for use in acne (apart from co-cypriniol which is licensed for severe acne) in the UK, but are known to be effective and are likely to have been prescribed for acne in some patients. However, UK primary care data do not link indications to prescriptions and therefore it is impossible to determine which $\mathrm{COC}$ were prescribed for acne and which were not.

Our estimate of acne consultation rates suggests a total number of primary care consultations $(934,000)$ that is considerably lower than the 3.5 million consultations per year that has been cited in a number of publications. ${ }^{13-15}$ The latter seems to have been extrapolated from data from a small (180 patients) French study of patients with severe acne, and therefore is unlikely to be representative of consulting behaviour for acne of all severities in the UK. ${ }^{16}$ Diagnoses are not always well recorded in primary care data, ${ }^{17}$ and follow-up consultations may use non-specific codes like 'patient reviewed' instead of a diagnostic code. Therefore, our data may underestimate the true incidence of primary care consultations for acne, and the follow-up rate following an initial consultation. However, Purdy et al. used similar primary care data in their study, and they undertook a validation process which found no primary care consultations for acne that had not been coded. ${ }^{18}$ Therefore, it seems likely that our data represent the most accurate estimate of primary care consultation rates for acne in the UK. There are few reliable measurements of overall acne prevalence in the UK, but if we use prevalence rates from the United States ${ }^{19}$ we can calculate an estimated total UK prevalence of around 8.1 million, suggesting that in any given year there is only 1 primary care consultation for every 8-9 patients with acne. This seems broadly consistent with a study of school children that found that less than a third of those with definite acne had ever consulted a doctor. ${ }^{20}$

A previous retrospective cohort study examined acne incidence using primary care records. They extracted data from 14 general practices in northeast England and reported an incidence of first consultations in 13-25 year olds over 12 months of 1.6\% (16 per 1,000 person-years), and a period prevalence (over 12 months) of acne (defined as anyone consulting or receiving medication for acne) of $3.1 \% .{ }^{18}$ Our consultation rates of 75.2 and 92.8 consultations per 1,000 patient years for $12-18$ year-old boys and girls respectively are clearly higher, but reflect total consultations rather than just first consultations. Our finding that the highest consultation rates are amongst teenagers is consistent with other studies, ${ }^{18,21-23}$ but we were also able to demonstrate that a considerable number of patients aged 30 years or over (especially women) consult for acne.

The same cohort study reported that in 2001/02 just over 50\% of males and a third of females were prescribed oral antibiotics first line, between a third and a quarter of males and females were prescribed non-antibiotic topical ARMs first line, and about $20 \%$ of males and a quarter of females 
were prescribed topical antibiotics first line. ${ }^{18}$ The proportion who were prescribed more than one medication was not described in this study, but the data are compatible with our finding that a large proportion of patients are treated with oral antibiotics first line. We have not been able to identify any other studies looking at follow-up consultations and ongoing prescribing, however an international cross-sectional survey of patients attending a follow-up appointment (1-3 months after a preceding acne consultation) identified that $58 \%$ of patients in Europe had poor adherence to acne medication. $^{24}$

The natural history of acne is not well described as there is a lack of high quality prospective cohort studies. However, acne is largely considered to be a chronic condition, with cross-sectional studies showing onset in the teenage years and persistence into the thirties of forties for many patients. ${ }^{1}$ As a chronic condition, and especially one where medication can take weeks or months to achieve maximal effect, ${ }^{25}$ and myths and misperceptions are common, ${ }^{26}$ ongoing care in the form of followup appointments is important. National Institute for Health and Care Excellence (NICE) Clinical Knowledge Summaries (CKS) guidance suggests that patients should be reviewed after six to eight weeks to assess treatment response and provide support. ${ }^{6}$ Therefore, our finding that two-thirds of patients have no follow-up consultations in the subsequent year, and that the majority of those that do consult do so more than three months after their initial consultation (which is longer than the typical duration of treatment prescribed), suggest that longitudinal acne care may be suboptimal in primary care. Some patients may have had mild acne and just wanted reassurance, and others may have been happy to use over the counter treatment and have no follow-up. Without data on severity it is not possible to determine the proportion falling into this category, but as three-quarters of new acne consultations involved prescribing an ARM and around a third of those being prescriptions for oral antibiotics, the numbers are unlikely to be high. Some may have been referred on to secondary care and this may explain their lack of follow-up in primary care. We did not extract data on referrals, but Purdy et al. reported that only $8.5 \%$ of patients were referred over a two-year follow-up period, ${ }^{18}$ so referral is unlikely to account for a large proportion of the patients who had no follow-up. Furthermore, we found that $60 \%$ of patients who are started on one or more ARMs were not prescribed any further ARMs in the subsequent 90 days. It is possible that some of these patients had a rapid resolution, and others may have moved on to using over the counter products, however these data suggest that a large proportion discontinued or poorly adhered to treatment before giving it sufficient opportunity to work. GPs have been encouraged to limit use of antibiotics and this may have contributed to the short duration of oral antibiotic prescribing. However, most guidance suggests that antibiotic treatment should be for at least 3-4 months, ${ }^{27}$ and that maintenance therapy with topical non-antibiotic treatments should be continued or initiated after oral antibiotics are 
stopped. Our data suggest limited use of prescription non-antibiotic treatments, either as single agents or in combination with oral antibiotics.

Around a third of patients with a new acne consultation who were treated with an ARM were prescribed only an oral antibiotic, a further third were prescribed only a topical antibiotic, and another $11 \%$ were prescribed both an oral antibiotic and a topical agent. Therefore, in total, just over three-quarters of initial acne therapy included an antibiotic. NICE CKS guidance for moderate acne recommends considering oral antibiotics only when there is extensive or difficult to reach acne on the back or when there is a significant risk of scaring or pigment change, and indicates that they should be combined with topical non-antibiotics. ${ }^{6}$ We do not know the severity, extent, or location of the acne in this study, and we do not know how many patients were using topical agents that they purchased over the counter. Nevertheless, these data suggest significant overuse of antibiotics in general and underuse of topical non-antibiotic treatment in those prescribed oral antibiotics. This is an important concern, given the increasing prevalence of resistant $P$ acnes, ${ }^{8}$ and the effects of antibiotic use for acne on resistance in other commensals ${ }^{28}$ and the development of respiratory tract infections. ${ }^{29}$ Our finding that oral tetracyclines were the most commonly prescribed oral antibiotics is consistent with guidance. ${ }^{6}$ There is good quality evidence supporting the use of BPO and topical retinoid alone or combined with a topical antibiotic, and these agents are recommended in guidelines. ${ }^{6,7}$ BPO is an effective antimicrobial, but does not promote the development of resistance, and topical retinoids play an important role in acne management because of their role in preventing comedogenesis. The increasing use of topical combined clindamycin/BPO) is therefore consistent with evidence, but the low use of topical retinoid and BPO that we found is concerning. Again, we have no information about how many of these patients were using topical agents purchased over the counter, but our data do suggest significant under-use of these agents.

In conclusion, our data suggest that the management of acne in primary care is sub-optimal and that consultation rates are relatively low for such a common condition. Management is over-reliant on antibiotic treatment (especially oral antibiotics) and under-utilises non-antibiotic treatments; oral antibiotics are frequently prescribed and in most cases they are prescribed without co-prescribing topical non-antibiotic treatments (increasing the risk of resistance and in contravention to guidelines), treatment courses are too short, and follow-up is less than optimal. Interventions to improve the management of acne in primary care need to be urgently developed and evaluated.

This article is protected by copyright. All rights reserved. 


\section{REFERENCES}

1 Bhate K, Williams HC. Epidemiology of acne vulgaris. British Journal of Dermatology 2013; 168:474-85.

2 Nijsten T, Rombouts S, Lambert J. Acne is prevalent but use of its treatments is infrequent among adolescents from the general population. Journal of the European Academy of Dermatology and Venereology : JEADV 2007; 21:163-8.

3 Walker N, Lewis-Jones MS. Quality of life and acne in Scottish adolescent schoolchildren: use of the Children's Dermatology Life Quality Index (CDLQI) and the Cardiff Acne Disability Index (CADI). Journal of the European Academy of Dermatology and Venereology : JEADV 2006; 20:4550.

4 Cotterill JA, Cunliffe WJ. Suicide in dermatological patients. Br J Dermatol 1997; 137:246-50.

5 Schäfer T, Nienhaus A, Vieluf D, et al. Epidemiology of acne in the general population: the risk of smoking. Br J Dermatol 2001; 145:100-4.

6 NICE Clinical Knowledge Summaries. Acne Vulgaris [WWW Document]. [accessed: 1/06/2016]. Available from: http://cks.nice.org.uk. doi:10.1002/14651858.CD004425.pub6/abstract.

7 Primary Care Dermatology Society. Acne Vulgaris [WWW Document]. [accessed: 1/06/2016]. Available from: http://www.pcds.org.uk/clinical-guidance/acne-vulgaris.

8 Walsh TR, Efthimiou J, Dréno B. Systematic review of antibiotic resistance in acne: an increasing topical and oral threat. The Lancet Infectious Diseases 2016; 16:e23-33.

9 Clinical Practice Research Datalink (CPRD). Available from: http://www.cprd.com/intro.asp.

10 Kousoulis AA, Rafi I, de Lusignan S. The CPRD and the RCGP: building on research success by enhancing benefits for patients and practices. Br J Gen Pract 2015; 65:54-5.

11 Bogart, S. Sankeymatic [WWW Document]. [Accessed: 3/9/2016]. Available from: http://sankeymatic.com.

12 StataCorp. 2013. Stata Statistical Software: Release 13. College Station, TX: StataCorp LP.

13 Dawson AL, Dellavalle RP. Acne vulgaris. BMJ 2013; 346:-f2634.

14 Purdy S, de Berker D. Acne. BMJ 2006; 333:949-53.

15 Newton JN. How cost-effective is oral isotretinoin? Dermatology (Basel) 1997; 195 Suppl 1:104-discussion38-40.

16 Lafarge H, Levy PE. Évaluation économique d'une innovation médica-menteuse: le traitement de I'acne sévère par Roaccutane. J Econ Med, 1987.

17 Francis NA, Hood K, Lyons R, Butler CC. Understanding flucloxacillin prescribing trends and treatment non-response in UK primary care: a Clinical Practice Research Datalink (CPRD) study. Journal of Antimicrobial Chemotherapy 2016; 71:dkw084-2046.

18 Purdy S, Langston J, Tait L. Presentation and management of acne in primary care: a

This article is protected by copyright. All rights reserved. 
retrospective cohort study. Br J Gen Pract 2003; 53:525-9.

19 White GM. Recent findings in the epidemiologic evidence, classification, and subtypes of acne vulgaris. J Am Acad Dermatol 1998; 39:S34-7.

20 Smithard A, Glazebrook C, Williams HC. Acne prevalence, knowledge about acne and psychological morbidity in mid-adolescence: a community-based study. Br J Dermatol 2001; 145:274-9.

21 Fellowes HM, Billewicz WZ, Thomson AM. Is acne a sign of normal puberty? A longitudinal study. J Biosoc Sci 1981; 13:401-7.

22 Goulden V, Stables GI, Cunliffe WJ. Prevalence of facial acne in adults. J Am Acad Dermatol 1999; 41:577-80.

23 Perkins AC, Maglione J, Hillebrand GG, et al. Acne vulgaris in women: prevalence across the life span. J Womens Health (Larchmt) 2012; 21:223-30.

24 Dréno B, Thiboutot $D$, Gollnick H, et al. Large-scale worldwide observational study of adherence with acne therapy. Int J Dermatol 2010; 49:448-56.

25 Ozolins M, Eady EA, Avery A, et al. Randomised controlled multiple treatment comparison to provide a cost-effectiveness rationale for the selection of antimicrobial therapy in acne. Health Technol Assess 2005; 9:iii-212.

26 Magin P. A systematic review of the evidence for 'myths and misconceptions' in acne management: diet, face-washing and sunlight. Family practice 2004; 22:62-70.

27 Dréno B, Thiboutot $D$, Gollnick $H$, et al. Antibiotic stewardship in dermatology: limiting antibiotic use in acne. Eur J Dermatol 2014; 24:330-4.

28 Levy RM, Huang EY, Roling D, et al. Effect of antibiotics on the oropharyngeal flora in patients with acne. Arch Dermatol 2003; 139:467-71.

29 Margolis DJ, Bowe WP, Hoffstad O, Berlin JA. Antibiotic treatment of acne may be associated with upper respiratory tract infections. Arch Dermatol 2005; 141:1132-6.

\section{TABLES}

Table 1-Acne consultations per 1,000 person-years by age and gender: 2004-2013

\begin{tabular}{|l|c|}
\hline Group & $\begin{array}{c}\text { Average } \\
\text { consultation rate }\end{array}$ \\
\hline $8-11$ Male & 0.8 \\
\hline $8-11$ Female & 4.8 \\
\hline $12-18$ Male & 75.2 \\
\hline $12-18$ Female & 92.8 \\
\hline 19-29 Male & 25.5 \\
\hline 19-29 Female & 53.5 \\
\hline $30+$ Male & 1.9 \\
\hline $30+$ Female & 6.4 \\
\hline
\end{tabular}

This article is protected by copyright. All rights reserved. 
Table 2 - Time to first follow-up consultation by age group

\begin{tabular}{|l|c|c|c|c|c|}
\hline \multirow{2}{*}{$\begin{array}{l}\text { Time to next } \\
\text { consultation }\end{array}$} & \multicolumn{4}{|c|}{ Age Group } & \multirow{2}{*}{ Total } \\
\cline { 1 - 5 } Within 30 days & $72(7.6)$ & $3,423(10.0)$ & $1,842(12.9)$ & $1,085(15.3)$ & $6,422(11.3)$ \\
\hline 31 to 60 days & $107(11.4)$ & $6,301(18.3)$ & $2,737(19.1)$ & $1,406(19.9)$ & $10,551(18.6)$ \\
\hline 61 to 90 days & $90(9.5)$ & $4,940(14.4)$ & $2,171(15.2)$ & $1,062(15.0)$ & $8,263(14.6)$ \\
\hline $\begin{array}{l}91 \text { days to } 6 \\
\text { months }\end{array}$ & $248(26.3)$ & $8,091(23.5)$ & $3,421(23.9)$ & $1,643(23.2)$ & $13,403(23.6)$ \\
\hline $\begin{array}{l}6 \text { months to } 1 \\
\text { year }\end{array}$ & $426(45.2)$ & $11,644(33.9)$ & $4,138(28.9)$ & $1,886(26.6)$ & $18,094(31.9)$ \\
\hline Total & 943 & 34,399 & 14,309 & 7,082 & 56,733 \\
\hline
\end{tabular}

Table 3-Acne related medications prescribed at an index acne consultation and during the subsequent 90 days and one year

\begin{tabular}{|l|c|c|c|c|c|c|c|c|c}
\hline \multirow{2}{*}{ ARM(s) prescribed } & \multicolumn{3}{|c|}{$\begin{array}{c}\text { Prescribing at index } \\
\text { consultation }\end{array}$} & \multicolumn{3}{c|}{$\begin{array}{c}\text { Prescribing during } \\
\text { subsequent 90 days }\end{array}$} & \multicolumn{2}{c}{$\begin{array}{c}\text { Prescribing during year } \\
\text { following index consultation } \\
\text { (including first 90 days) }\end{array}$} \\
\cline { 2 - 11 } & $\mathrm{N}$ & $\%^{*}$ & $\%^{\#}$ & $\mathrm{~N}$ & $\%^{*}$ & $\%^{\#}$ & $\mathrm{~N}$ & $\%^{*}$ & ${ }^{*}$ \\
\hline No ARM & 44,809 & 26.7 & - & 113,131 & 67.5 & - & 78,567 & 46.9 & - \\
\hline $\begin{array}{l}\text { Oral antibiotic } \\
\text { alone }\end{array}$ & 41,791 & 24.9 & 34.0 & 25,793 & 15.4 & 47.4 & 32,750 & 19.5 & 36.8 \\
\hline $\begin{array}{l}\text { Topical antibiotic } \\
\text { (including } \\
\text { combinations) } \\
\text { alone }\end{array}$ & 39,529 & 23.6 & 32.2 & 11,004 & 6.6 & 20.2 & 16,806 & 10.0 & 18.9 \\
\hline $\begin{array}{l}\text { Topical non- } \\
\text { antibiotic alone }\end{array}$ & 20,875 & 12.5 & 17.0 & 4,250 & 2.5 & 7.8 & 6,458 & 3.9 & 7.3 \\
\hline $\begin{array}{l}\text { Oral antibiotic + } \\
\text { topical non- } \\
\text { antibiotic }\end{array}$ & 9,168 & 5.5 & 7.5 & 5,711 & 3.4 & 10.5 & 12,009 & 7.2 & 13.5 \\
\hline $\begin{array}{l}\text { Oral antibiotic+ } \\
\text { topical antibiotic }\end{array}$ & 4,671 & 2.8 & 3.8 & 3,666 & 2.2 & 6.7 & 11,215 & 6.7 & 12.6 \\
\hline $\begin{array}{l}\text { Co-cyprindiol } \\
\text { alone }\end{array}$ & 4,014 & 2.4 & 3.3 & 2,433 & 1.5 & 4.5 & 3,987 & 2.4 & 4.5 \\
\hline $\begin{array}{l}\text { Co-cyprindiol + } \\
\text { any topical agent }\end{array}$ & 793 & 0.5 & 0.6 & 564 & 0.3 & 1.0 & 2,265 & 1.4 & 2.5 \\
\hline $\begin{array}{l}\text { Oral isotretinoin } \\
\text { alone }\end{array}$ & 15 & 0.0 & 0.0 & 36 & 0.0 & 0.1 & 47 & 0.0 & 0.1 \\
\hline $\begin{array}{l}\text { Oral isotretinoin + } \\
\text { other ARM }\end{array}$ & 2 & 0.0 & 0.0 & 8 & 0.0 & 0.0 & 98 & 0.1 & 0.1 \\
\hline Other combination & 1,906 & 1.1 & 1.6 & 977 & 0.6 & 1.8 & 3,371 & 2.0 & 3.8 \\
\hline Total & 167,573 & 100 & 100 & 167,573 & 100 & 100 & 167,573 & 100 & 100 \\
\hline $\begin{array}{l}* \\
\text { * Proportion of total } \\
\text { Proportion of those who were prescribed an ARM }\end{array}$ & & & & & & & \\
\hline
\end{tabular}

This article is protected by copyright. All rights reserved. 
Table 4 - Quantity of ARM medication prescribed per prescription

\begin{tabular}{|l|c|c|}
\hline Medication & $\begin{array}{c}\text { Quantity per } \\
\text { prescription - } \\
\text { median (IQR) }\end{array}$ & $\begin{array}{c}\text { Equivalent } \\
\text { number of days } \\
\text { (approximately) }\end{array}$ \\
\hline Oral antibiotics & $112(112,120)$ & 28 \\
\hline Oxytetracycline & $50(28,56)$ & 25 \\
\hline Doxycycline & $56(28,56)$ & 56 \\
\hline Lymecycline & $56(56,56)$ & 28 \\
\hline Minocycline & $112(56,112)$ & 28 \\
\hline Other tetracyclines & $100(42,112)$ & $25^{\#}$ \\
\hline Erythromycin & $63(63,126)$ & 84 \\
\hline Oral hormonal & $50(30,50)$ & 50 \\
\hline Co-cyprindiol & $50(50,50)$ & 50 \\
\hline Topical & $25(25,50)$ & 50 \\
\hline Clindamycin & $30(25,47)$ & $30-60$ \\
\hline Erythromycin & $40(40,60)$ & $40-80$ \\
\hline Clindamycin/BPO & $50(25,50)$ & $33-50$ \\
\hline Erythromycin/retinoid & $30(30,30)$ & $30-60$ \\
\hline BPO & $60(30,60)$ & $60-120$ \\
\hline BPO/hydroxyquinolone & $45(45,45)$ & 90 \\
\hline Azelaic acid & $45(45,45)$ & 90 \\
\hline Retinoids & \\
\hline Adapalene & \multicolumn{2}{|l|}{} \\
\hline Adapalene/BPO & $\begin{array}{l}\text { *For topical agents a rough guide of 0.5g (equivalent to the size of } \\
\text { two palm areas) per application was used } \\
\text { \# 87\% of erythromycin tablets were 250mg }\end{array}$ \\
\hline
\end{tabular}

\section{FIGURES}

Figure 1: Acne consultation rates by age and gender: $2004-2013$ $<$ Insert figure 1>

Figure 2: Oral acne related medication prescribing: $2004-2013$ $<$ Insert figure 2>

Figure 3 - Topical acne related medication prescribing: $2004-2013$ $<$ Insert figure 3>

Figure 4 - Sankey diagram of acne related medication (ARM) prescribing at an index consultation and over the subsequent 90 days

$<$ Insert figure 4>

This article is protected by copyright. All rights reserved. 

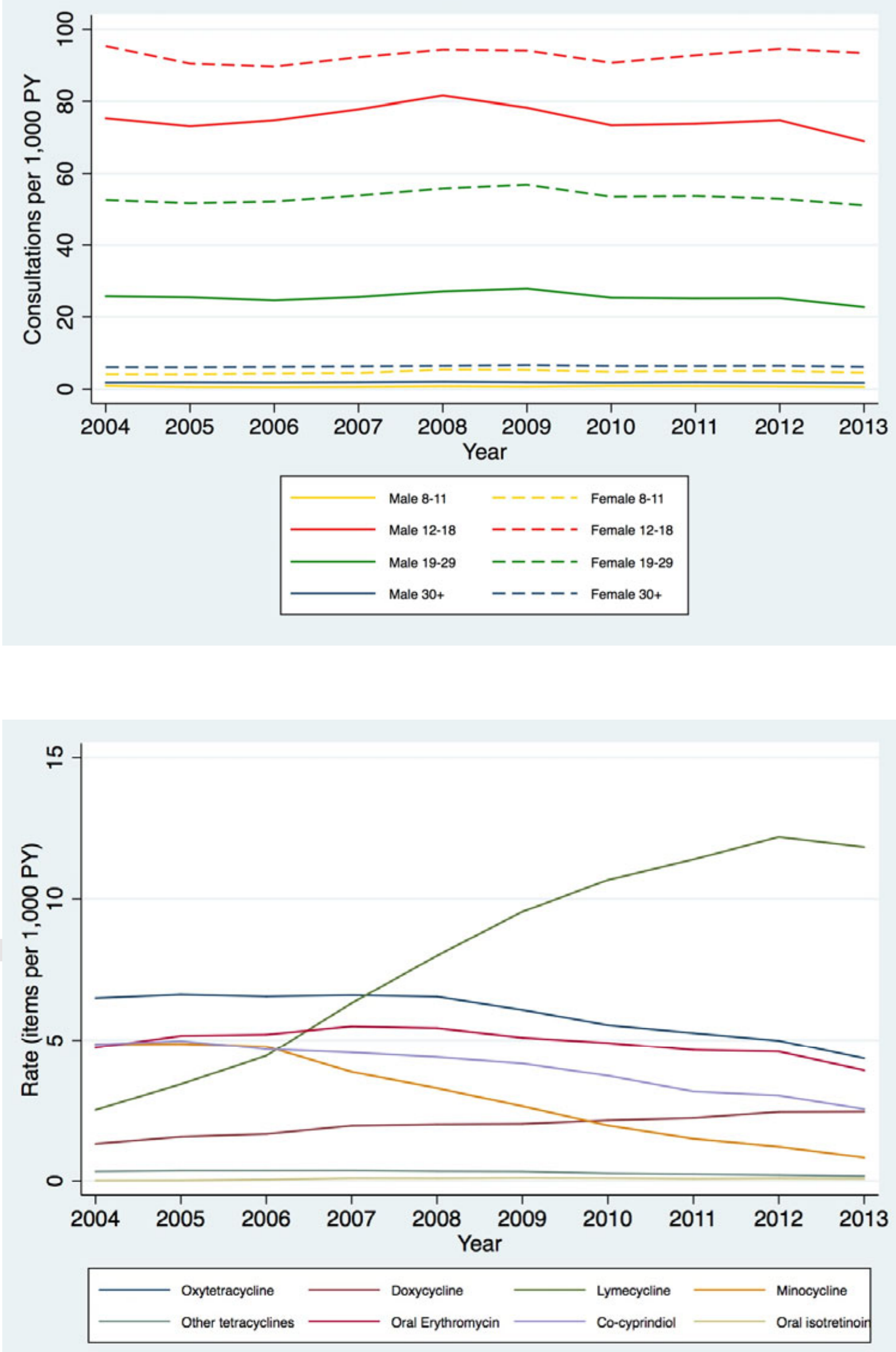

This article is protected by copyright. All rights reserved. 


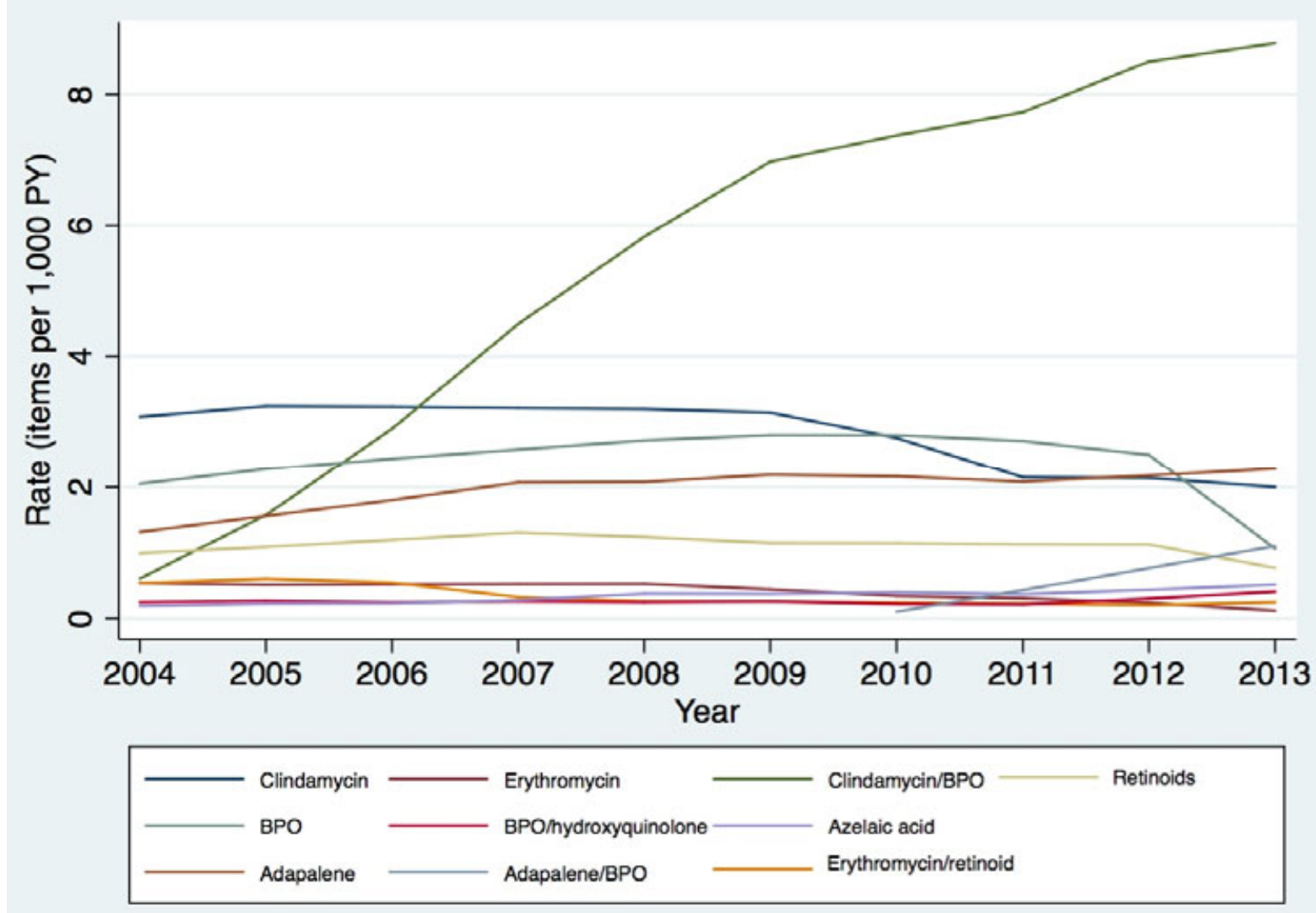

This article is protected by copyright. All rights reserved. 


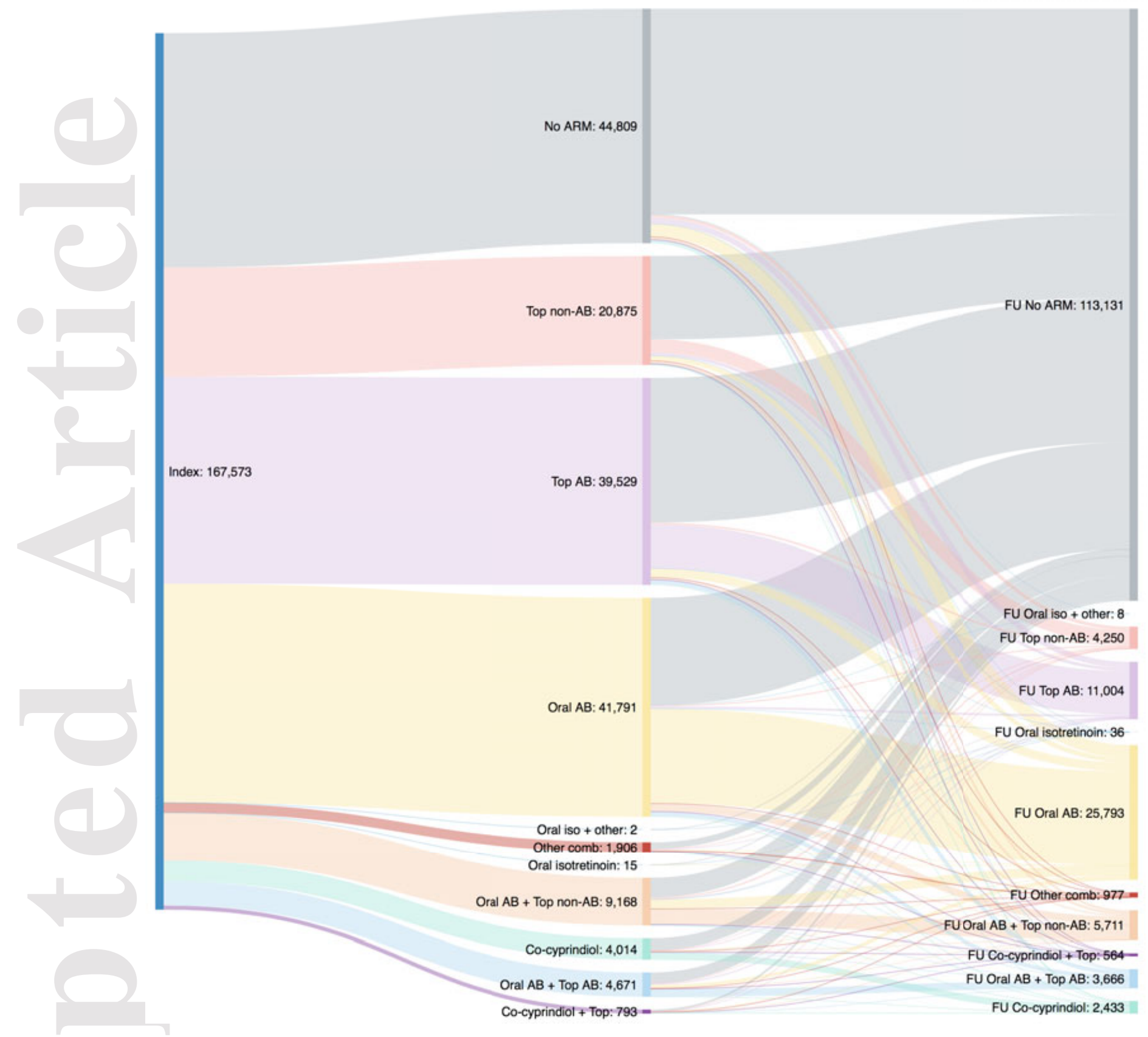

This article is protected by copyright. All rights reserved. 